\title{
Nueva institucionalidad en el sistema portuario argentino: vinculación público/privada en la organización y gestión del puerto Quequén
}

\author{
Ana María Costa \\ Susana SiLvia Brieva \\ LILIANA IRIARTE*
}

\begin{abstract}
This paper proposes to analyse the organising and managerial experience of the Consorcio de Gestión del Puerto Quequén -Quequén Port Management Consortium - and reflect on its economical, social, political and territorial effects as a the result of the port decentralisation and privatisation. From this analysis we observe that there are still some inefficiencies and governance problems, even if there is an improvement in the indices of economic efficiency that provide the port with greater competitiveness, and in spite of the fact that the decentralisation has promoted a greater participation of the different actors in the port activities. The problems and inefficiencies mentioned above are derived from the coexistence of different logics among the diverse groups of interest that participate in the port management.
\end{abstract}

Keywords: Argentina, ports, management, privatisation, institutionality.

\section{Resumen}

En este trabajo se propone analizar la experiencia organizativa y de gestión del Consorcio de Gestión del Puerto Quequén, y reflexionar acerca de sus efectos económicos, sociopolíticos y territoriales resultantes de la descentralización y privatización portuarias. Del análisis surge que si bien existe una mejora en los indicadores de eficiencia económica que otorgan mayor competitividad al puerto, y que la descentralización ha promovido una mayor participación del conjunto de actores involucrados en la actividad, aún existen ineficiencias y problemas de gobernabilidad derivados de la coexistencia de lógicas diferentes entre los distintos grupos de interés que participan en la gestión portuaria.

Palabras clave: Argentina, puertos, gestión, privatización, institucionalidad.

* Departamento de Ciencias Sociales, Facultad de Ciencias Agrarias, Universidad Nacional de Mardel Plata. Correos-e: amcosta@copetel.com.ar, sbrieva@balcarce.inta. gov.ar y liriarte@balcarce.inta.gov.ar. 


\section{Introducción}

La globalización, la consolidación de bloques regionales y la creciente competencia de los mercados internacionales han causado un aumento en los volúmenes de comercio por vía marítima, donde el sistema portuario adquiere un nuevo significado, a la vez que se constituye en un escenario de profundos cambios institucionales, tecnológicos y organizacionales.

En Argentina, el sector portuario no ha permanecido ajeno a estas tendencias, especialmente a partir de las transformaciones económicas, sociales y políticas ocurridas en la década de los noventa, mediante el programa de privatización de las empresas e infraestructura pública. Este proceso fue acompañado por la desregulación de los mercados, la flexibilidad laboral y la apertura económica, que en los puertos nacionales impulsa una profunda reestructuración.

A partir de la reforma institucional surgen nuevas formas de articulación público/privada en la organización y gestión portuaria que se basan en el modelo denominado Landlord, donde el sector público conserva la propiedad del puerto e invierte en infraestructura básica, pero no explota en general ninguno de los servicios que se prestan al buque o a las cargas. En este nuevo modelo se constituyen los consorcios de gestión ${ }^{1}$ como forma de administrar un puerto, caracterizados por la autonomía económica, financiera y contable, pero auditados y controlados por el Estado provincial.

Distintos estudios (Hoffmann, 1999; FIEL, 1999; Gardel, 2000; Thomson, 1999; Nombela, y Trujillo, 2000; Cepal, 1992) señalan la eficiencia económica alcanzada por el sistema portuario después de las reformas sin profundizar en la dinámica alcanzada por el nuevo esquema organizativo y de gestión.

Ante el interrogante respecto de los alcances de la articulación público/privada en la gestión de los puertos del país, el objetivo de

\footnotetext{
${ }^{1}$ Los consorcios son organizaciones con personalidad jurídica pública de naturaleza asociativa con carácter no territorial, constituidas voluntariamente por diversas administraciones públicas, o por éstas con determinadas entidades privadas, que tengan finalidades concurrentes de interés público. Su finalidad consiste en la prestación de servicios públicos y, en general, cualquier actividad que se recoja en su acta de constitución. Su instauración proviene de la realización previa de un convenio de colaboración y de la necesidad de establecer una organización común para gestionar el contenido del convenio. Los estatutos deben especificar los regímenes orgánico, funcional y financiero del consorcio. La legislación de la figura consorcial es una de las más confusas, y quizá debido a ello ha sido utilizada como herramienta de innovación en la gestión de los servicios públicos.
} 
este texto es analizar la experiencia organizativa y de gestión del Consorcio del Puerto Quequén, así como reflexionar acerca de los efectos socioeconómicos, sociopolíticos y territoriales resultantes de la descentralización y privatización portuarias.

Como hipótesis de trabajo se plantea que a pesar de la eficiencia económica lograda mediante la acción conjunta público/ privada en el Consorcio de Gestión del Puerto de Quequén, aún existen ineficiencias y problemas de gobernabilidad derivados de la coexistencia de lógicas diferentes entre los actores sociales involucrados en la actividad portuaria.

Desde un enfoque institucional que integra conceptos teóricos provenientes de la ciencia económica, la geografía y la sociología, este trabajo se estructura de la siguiente manera: en primer lugar se hace referencia a la localización, especialización y eficiencia alcanzadas por el puerto Quequén desde 1994 a la fecha. Luego se describen los cambios en la administración y gestión del puerto que devienen de la conformación del Consorcio de Gestión, y se identifican los principales actores privados que participan en las decisiones de este nuevo ente.

Posteriormente, con base en la noción de campo de Pierre Bourdieu (1999), se analizan los conflictos e intereses que se ponen en juego en el seno de la organización conjunta entre el sector público y el privado.

Por último, como conclusión, se presentan algunas consideraciones acerca de la especialización y eficiencia económica alcanzadas a partir de 1994 por el Consorcio del Puerto Quequén, la participación de los actores y la existencia de lógicas distintas entre los diferentes agentes involucrados en la actividad, así como también acerca de las potencialidades, límites y gobernabilidad de este esquema de vinculación público/privada en el sistema portuario argentino.

\section{Enfoque teórico y estrategia metodológica}

Para cumplir con el objetivo propuesto, en este estudio se recure a un diseño de investigación cuali-cuantitativo que combina conceptos provenientes de tres matrices disciplinarias: la economía, la geografía y la sociología.

Desde la perspectiva de la economía institucional, la comunidad portuaria constituye una configuración intermedia entre el mercado y la empresa. Se trata de un dispositivo contractual formal que rige las relaciones de competencia de naturaleza con- 
flictiva y, al mismo tiempo, de cooperación entre las empresas que intervienen en el transporte y los puertos.

De la geografía se adoptan los conceptos de espacio económico, hinterland y estrategia espacial. Se entiende por el primero el campo de formación de estrategias, confrontación de fuerzas y consensos entre los agentes y grupos económicos. Por su parte, hinterland se define como el área de influencia o espacio económico organizado alrededor de un puerto, mientras que estrategia espacial hace referencia a las decisiones de localización que adoptan las empresas para alcanzar objetivos y fines específicos.

Por último, desde la vertiente sociológica, en el análisis del comportamiento de la organización y las interrelaciones entre los distintos actores sociales involucrados se adopta el concepto de campo desarrollado por Bourdieu (1999). En este caso, la unidad de análisis es la organización o campo, representado por los actores sociales que intervienen en la comunidad portuaria (funcionarios, sindicatos y empresas). Este campo es el espacio de relaciones de fuerza o de luchas donde hay intereses puestos en juego y donde los distintos agentes e instituciones ocupan posiciones diferentes según el capital específico que poseen, y elaboran distintas estrategias para defender su capital -el que pudieron acumular en el curso de luchas anteriores-. En el seno de cada campo, la jerarquía establecida es continuamente puesta en tela de juicio, y los principios mismos que subyacen en la estructura del campo pueden ser impugnados y cuestionados.

Para Bourdieu, el capital es trabajo acumulado, bien en forma de materia o en forma interiorizada o incorporada. Es decir, se considera el concepto de capital en todas sus manifestaciones y no sólo en la forma en que la reconoce la teoría económica. El concepto económico de capital reduce el universo de las relaciones sociales de intercambio al simple intercambio de mercancías, el que está objetiva y subjetivamente orientado hacia la maximización de beneficio. De esta manera, la teoría económica define implícitamente todas las demás formas de intercambio social como relaciones no económicas y desinteresadas. Sin embargo, en la visión de Bourdieu el capital puede presentarse de tres formas fundamentales: el capital económico, que es directa o indirectamente convertible en dinero y resulta especialmente indicado para la institucionalización de los derechos de propiedad; el capital cultural, que puede convertirse, en ciertas condiciones, en capital económico y resulta apropiado para la institucionalización; y por último el capital social, que es un capital de 
obligaciones y relaciones sociales y resulta igualmente convertible, en ciertas condiciones, en capital económico y puede ser institucionalizado. El capital social está constituido por la totalidad de los recursos potenciales o actuales asociados a la posesión de una red duradera de relaciones más o menos institucionalizadas de conocimiento y reconocimientos mutuos, es decir, de la totalidad de recursos basados en la pertenencia a un grupo.

La desigual distribución de capital en la estructura total del campo da origen a los conflictos por la distinta capacidad de apropiarse de los beneficios y de imponer reglas de juego favorables a cada capital, y donde los agentes luchan de acuerdo con la posición que ocupan. A medida que los conflictos y luchas van progresando, van modificándose el peso y las formas del capital, y por lo tanto se modifica la estructura del campo al hacerlo una estructura dinámica. En esta perspectiva, las nociones de campo y capital son estrechamente interdependientes, por lo que es importante no sólo delimitar el campo sino también determinar qué tipos de capitales operan en él. En este caso, los capitales de mayor importancia en la conformación del capital global de la organización son el capital sociopolítico y el económico.

Para comprender la estructura de gobernación o governance ${ }^{2}$ de las nuevas formas organizativas, se tienen en cuenta las nociones de costos de transacción que surgen de la sucesión de transacciones que se realizan a lo largo de una cadena productiva, en el marco del ambiente institucional y organizacional en la búsqueda de una mayor eficiencia. En esta sucesión de arreglos contractuales, algunos pueden mostrar mayores niveles de eficiencia en la coordinación y se expanden al conjunto del subsistema. En el caso de cadenas globalizadas como la granaria, la noción de governance ha sido utilizada para aludir a la presencia de ciertas firmas con capacidad para establecer e imponer los parámetros desde los cuales operan otras empresas de la cadena.

La idea de governance desde el sector público ofrece dos significaciones: por un lado, en el enfoque de corte neoliberal, este concepto refleja la fusión público/privada tendente a estimular la participación de estos ámbitos y a reducir las fallas de mercado resultantes de la excesiva intervención estatal. Por otro, para

${ }^{2}$ La governance o gobernabilidad se refiere a la capacidad de una determinada sociedad para enfrentar positivamente los desafíos y oportunidades que se plantean en determinado momento. Gobernabilidad no es, entonces, estabilidad política, sino establecimiento de condiciones para reconocer y enfrentar colectivamente los desafíos y las oportunidades de cada época. 
la visión regulacionista y para los teóricos de las convenciones, la governance es la configuración de un conjunto de relaciones institucionales complejas. En otras palabras, puede entenderse como el conjunto de modos de regulación entre el mercado y la política (el Estado), que a su vez comprende la coordinación formal e informal en los distintos niveles. Esta perspectiva tiende a contraequilibrar las conductas competitivas de las empresas y a estimular la cooperación y el desarrollo conjunto.

En cuanto a la estrategia metodológica, en primer lugar se recopila, sistematiza y analiza información estadística referida a volúmenes y composición de las exportaciones e importaciones, principales destinos, días de espera, costos del buque en el puerto, entre otros, que se encuentra disponible en organismos públicos y privados ligados a la actividad. En segundo lugar se realiza un análisis crítico de la Ley núm. 24.093 de Actividades Portuarias, sus decretos reglamentarios, y la Ley Provincial núm. 11.414 que promueve la conformación del Consorcio de Gestión.

Para el análisis de la organización y gestión del puerto se compara la información contenida en diarios de difusión nacional y regional, y la surgida de la realización de entrevistas no estructuradas a informantes clave o referentes en el tema y oferentes y demandantes del servicio. Con esta técnica busca reconstruirse el pasado y el presente de los actores, a la vez que tratan de visualizarse las condiciones en que se desarrolla el sistema seleccionado, sus interacciones formales e informales y el desenvolvimiento de los actores frente a los conflictos y su resolución.

Por último, en la búsqueda de las particularidades estructurales, de los alcances y las limitaciones de la nueva organización, se realiza una periodización que permite describir la dinámica de la nueva figura de gestión e identificar dos momentos o etapas en la trayectoria del consorcio de acuerdo con el liderazgo o predominio del capital sociopolítico o el capital económico en las decisiones.

En cada etapa se analiza la participación específica de los principales actores involucrados y se detectan los conflictos emanados del flujo de información y el poder que ejerce cada uno de estos agentes sociales en este espacio económico. Este análisis se realiza de forma subjetiva mediante la noción de campo, que permite circunscribirlo a un espacio concreto y a un conjunto de actores sociales determinados que articulan tanto la lógica global como la local. 


\section{Localización, especialización y eficiencia económica del puerto Quequén}

La posición geográfica de Argentina, distante de los grandes centros de consumo, hace que el transporte por agua represente el medio más apropiado para la movilización de grandes volúmenes de carga de exportación e importación. Por vía marítima se canaliza 95\% del volumen total de las exportaciones y cerca de $80 \%$ del volumen total de las importaciones del país.

En Argentina, los 15 principales puertos, que embarcan mayoritariamente productos de origen agropecuario, pueden dividirse en dos grupos: fluviales (12) y marítimos (3). Los primeros se concentran en las cercanías de las zonas productivas del norte y centro del país, sobre las márgenes del río Paraná hasta La Plata, mientras que los segundos se localizan en la costa atlántica hasta Bahía Blanca, en el sur de la provincia de Buenos Aires. Este sistema fluviomarítimo ofrece gran variedad de alternativas para el flujo de mercaderías, tanto para el tránsito interno como para la exportación.

Durante el último quinquenio, por los puertos fluviales se ha canalizado el mayor volumen $(80 \%)$, mientras que por los puertos marítimos se ha exportado el $20 \%$ restante. Dentro de estos últimos, Quequén desempeña 44\% del total del volumen embarcado.

Este puerto se encuentra localizado al sur de la provincia de Buenos Aires (véase mapa I), en el centro de la región más fértil de la llanura templada argentina, en la desembocadura del río homónimo, con un área de influencia de $300 \mathrm{~km}$ de radio, y conectado con los centros de producción y consumo, principalmente del sudeste de la provincia, y con las principales rutas del Mercado Común del Sur (Mercosur).

Una de las ventajas propias de Quequén es su proximidad al océano Atlántico, donde alcanza profundidades de 46 pies a sólo 1,500 metros de la boca de entrada al puerto, y un calado de 40 pies en el canal de acceso, ${ }^{3}$ condiciones que lo hacen el tercer puerto de aguas profundas de la Argentina, después de puerto Madryn en la Patagonia (48 pies) y Bahía Blanca en el sur de la provincia de Buenos Aires (45 pies). Si bien el fácil acceso al océano y la profundidad son dos elementos importantes en la

\footnotetext{
${ }^{3}$ El canal de acceso tiene un ancho de 120 metros, y una profundidad a la tosca en la zona protegida de 14 metros (46 pies). Está localizado sobre un área no sedimentada de la costa de la provincia de Buenos Aires, por lo que mantenerlo sólo requiere trabajos de dragado que en su totalidad no superan los 0.6 millones de metros cúbicos por año.
} 


\section{Mapa I \\ Localización y área de influencia del puerto Quequén}

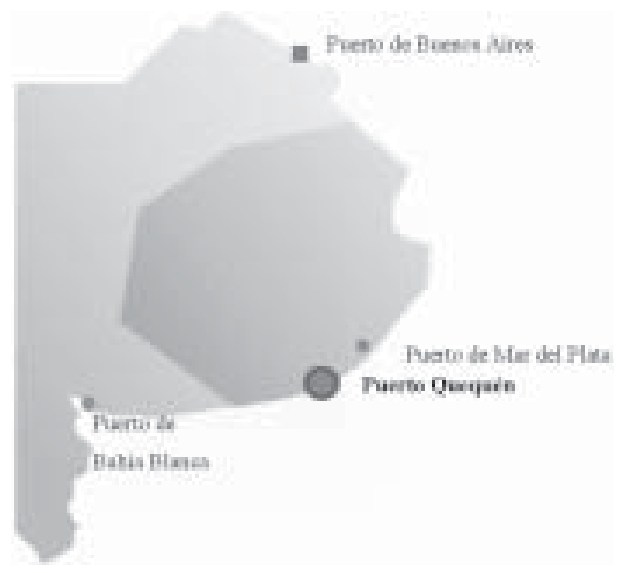

Fuente: Extraído de la página web del puerto Quequén (http://www.puertosdeargentina. com.ar/Atlantico/quequen.htm).

operatoria portuaria, la fuerte exposición a los vientos provenientes del Atlántico implican ciertas desventajas para el puerto desde el punto de vista natural, que exigen inversiones y una organización de los embarques según las condiciones de navegabilidad a raíz de las condiciones meteorológicas. ${ }^{4}$

El puerto Quequén posee un importante hinterland que abarca 11 partidos del sudeste bonaerense con aproximadamente 4.6 millones de hectáreas de excelente calidad para la producción agropecuaria, que en los últimos años muestra una tendencia creciente en la producción de maíz, trigo, girasol y soja. Los límites del hinterland se definen por la influencia del resto de los puertos marítimos, en este caso representados por Bahía Blanca y, más recientemente, por la incorporación de Mar del Plata ${ }^{5}$-tradicional puerto pesquero- para la exportación de productos agropecuarios.

La especialización en los embarques de granos de trigo y maíz, en el puerto Quequén, está asociada a características agroecológicas de su hinterland, que abarca una importante zona de pro-

${ }^{4}$ Este puerto se cierra cuando los vientos superan los $37 \mathrm{~km} / \mathrm{h}$ en el caso de los buques de ultramar, y los $50 \mathrm{~km} / \mathrm{h}$ para los pesqueros de altura, y cuando las olas alcanzan 1.85 y $3.5 \mathrm{~m}$, respectivamente. En promedio permanece cerrado 60 días al año, aunque en el año 2001, por la adversidad de las condiciones meteorológicas, el puerto estuvo cerrado 100 días.

${ }^{5}$ Recientemente, por este puerto se embarcó en un buque panameño, por primera vez, trigo seleccionado de alta calidad para panificación, con destino a un molino brasileño. 
ducción de estos cultivos. Los mayores volúmenes exportados por este puerto están relacionados más con los aumentos en la producción agropecuaria de la región que con la expansión del radio de acción del consorcio. Mientras que desde mediados de la década de 1980 hasta mediados de la siguiente la producción de cereales más que se duplicó en el sudeste bonaerense, el incremento de los embarques de trigo y maíz por el puerto Quequén alcanzó $70 \%$ en el mismo periodo.

Por otra parte, la estrategia de ampliación del hinterland se encuentra constreñida tanto al desmantelamiento de las vías férreas que lo conectaban con la zona de producción y con otras líneas ferroviarias, como por el límite que le imponen la Cuenca del Salado y la depresión de Laprida, que por sus condiciones agroecológicas permite actividades predominantemente ganaderas. En mejor posición se encuentran los puertos de Rosario y Bahía Blanca, que han mantenido las conexiones con los ramales ferroviarios -los que también han sido privatizados-, y por la expansión de la frontera agrícola con girasol y soja hacia el interior del territorio; esto redunda en mayores volúmenes de producción con destino al exterior.

En cuanto a la competitividad y eficiencia económica alcanzadas por este puerto, cabe recordar que no sólo se basan en obtener un costo bajo del servicio, sino que es necesario además lograr un rendimiento operativo que permita al buque optimar su tiempo de estadía evitando demoras ociosas en los muelles y en las zonas de espera.

Uno de los indicadores más importantes de performance de un puerto, y que tiene gran incidencia en su competitividad, es la tarifa que cobran los elevadores portuarios que operan en él, dado que un exportador opera con aquella terminal que le ofrezca, además de un buen servicio, un precio competitivo.

Este puerto posee dos terminales portuarias pertenecientes a la Asociación de Cooperativas Argentinas (ACA) y a la Terminal Quequén, s.A., ${ }^{6}$ que admiten una recepción de 1,300 camiones por día. Buena parte de la actual infraestructura en elevadores de granos que posee este puerto fue construida, a partir de 1945,

${ }^{6}$ La Terminal Quequén, S.A. está conformada por un grupo de empresas privadas nacionales e internacionales como Genaro García, Nidera, Oleaginosa Moreno, Tradigrain, La Plata Cereal, Productos Sudamericanos, Bunge y Born Comercial, ACA, Sociedad Rural, Centro de Corredores, Bolsa de Cereales de Buenos Aires y Centro de Acopiadores. 
por la Junta Nacional de Granos, ${ }^{7}$ hasta su privatización en 1992. El primer antecedente de traspaso de activos públicos al sector privado data de 1985, cuando se habilitó el servicio de la terminal perteneciente a la ACA y a la Federación Argentina de Cooperativas Agrícolas (FACA), que cuenta con una capacidad de almacenaje de 200,000 ton para granos y un ritmo de carga de 1,600 ton/h. Los embarques de aceite se producen a un ritmo de carga de 800 ton/h y con una capacidad de almacenaje de 10,800 ton.

La Terminal Quequén, S.A., concesionaria desde 1992 de la infraestructura de silos de la ex Junta Nacional de Granos, posee una capacidad de almacenaje de 117,000 ton de granos, con un ritmo de carga de 1,700 ton/h.

En los últimos años, en Quequén se redujo el tiempo de estadía de los buques, de aproximadamente ocho días en la década de los años ochenta, a un promedio de dos a tres días a fines de la década de los noventa, lo que redujo sensiblemente los costos variables y generó un ahorro de alrededor de 20,000 dólares por buque.

Además, Quequén es el más barato de los puertos argentinos, dado que no es necesario el uso de algunos servicios como dragado y pilotaje de canales. Estos costos son significativos para un buque tipo Panamax, que puede cargar alrededor de 52,000 ton, ya que le representan en promedio una erogación de 25,000 dólares más. No obstante, Quequén tiene la desventaja ejercida por las olas oceánicas y locales que se forman en la entrada del puerto, que juegan en este caso un papel preponderante en los costos variables, pues una mayor estadía implica mayores costos por tonelada para el armador que luego se trasladan al costo del flete (Gardel, 1999: 17-18).

En cuanto a los costos portuarios (estadía en puerto, piloto, remolcador, vigilancia, etc.) en términos relativos, entre 1990 y el 2000 han crecido alrededor de 60\% promedio; sin embargo, debe considerarse que el incremento de la capacidad del ritmo de carga y el aumento de la capacidad de almacenaje de los puertos, así como la facilidad de la mayor amplitud de la bodega de los buques y la eliminación -gracias al dragado- de un puerto de

${ }^{7}$ En 1956 se erigió en Argentina la Junta Nacional de Granos (JNG), organismo que tendría a su cargo el control de todas las instituciones o entidades que intervienen directa o indirectamente en el comercio interno y externo de granos, oleaginosas y subproductos. El proceso de Reforma del Estado llevó a su disolución en 1994; transfirió a la Secretaría de Agricultura, Ganadería, Pesca y Alimentación (SAgpya) las funciones de política comercial interna y externa de productos agropecuarios que correspondían a este organismo. 
completamiento, permiten la reducción del tiempo de estadía de las naves (SAGPya, 2002: 19).

La situación geográfica del puerto y su proximidad a las zonas de producción en el caso de que el puerto sea exportador, o a las zonas intensamente pobladas en el caso que éste sea importador, son aspectos fundamentales para su viabilidad. Según Cristian Gardel (1999), el hinterland es una condición necesaria, pero no suficiente, para el desarrollo portuario; señala que los costos, la estadía de un buque en puerto y la profundidad de las vías navegables son los indicadores más explicativos del éxito comercial de los puertos.

La concepción de puerto como puerta de entrada, propia de fines de los años cincuenta, considera al hinterland como una extensión delimitada donde el factor clave de desarrollo pasa por el puerto, y su competitividad es el resultado del acceso diferencial a las zonas de producción o abastecimiento interno; el éxito o fracaso de cada puerto depende de la capacidad de ampliar su influencia económica en relación con sus competidores.

Más tarde, en los años setenta, la idea de hinterland cambió y se vio al puerto como un eslabón más de la cadena logística que se articula con un sistema multimodal de transporte. En el caso de Quequén parece primar aún la vieja idea de puerto y de hinterland de los cincuenta, típica de la especialización productiva (commodities agropecuarios y agroindustriales).

\section{Cambios en la administración y gestión portuaria argentina: el Consorcio de Gestión del Puerto Quequén}

Frente a la creciente globalización económica, la tendencia internacional es la modernización los puertos estatales, es decir, de aquellos administrados y operados por los gobiernos, lo que privilegia la acción del mercado como un eficaz ordenador de la actividad económica. De esta forma busca responderse a las nuevas exigencias de competitividad y lograr mayor eficiencia y racionalidad económica del conjunto del sistema productivo. ${ }^{8}$

Respecto a la propiedad de los 50 principales puertos del mundo, $82 \%$ son de propiedad mixta, $12 \%$ son de propiedad pública, y sólo $6 \%$ corresponde a propiedad privada.

\footnotetext{
${ }^{8}$ El Reino Unido representa la experiencia pionera de este modelo que privilegia la participación privada.
} 
En Argentina, durante la década de 1990 los cambios más significativos ocurrieron en la esfera institucional, que en el sistema portuario se materializaron mediante un conjunto de decretos sancionados en el marco de la Reforma del Estado (Ley núm. 23.696/ 89) entre los años 1989 y 1993 que apuntan a la desregulación de los servicios y a la eliminación de algunos entes públicos como paso previo a la sanción de la Ley de Actividades Portuarias núm. 24.093 y su decreto reglamentario núm. 817 en 1992.

Los ejes centrales de esta Ley de Actividades Portuarias son: a) la descentralización ${ }^{10}$ de la gestión político-administrativa (transferencia de todos los puertos a las provincias e instalación de puertos autónomos); $b$ ) la privatización de la gestión operativa a partir de la concesión ${ }^{11}$ de las terminales portuarias que pertenecían hasta ese momento a la Junta Nacional de Granos, que se encuentran emplazadas en los diferentes puertos, y la prestación de servicios portuarios, y $c$ ) el establecimiento y tenencia definitiva de puertos privados. ${ }^{12}$

\footnotetext{
${ }^{9}$ Esta ley dispuso la transferencia (a título gratuito) hacia las provincias del dominio y explotación de los puertos del Estado nacional que estuvieran situados en sus territorios. Para los casos especiales de Buenos Aires, Rosario, Bahía Blanca, Quequén y Santa Fe, dicha transferencia se condicionó a que previamente se hubieran constituido sociedades de derecho privado o entes públicos no estatales que asumieran la administración de cada uno de estos puertos.

${ }^{10}$ La descentralización constituye un amplio espectro de reformas económicas, administrativas y sobre todo políticas que apuntan a un ajuste de la regulación estatal frente a la sociedad. Esta nueva forma de organización administrativa viene a cristalizar el proceso de descentralización y mayor participación de las comunidades locales, muy en boga en la década de los ochenta, a partir del reestablecimiento de las democracias en gran parte de los países latinoamericanos. Entre las razones que por entonces justificaban la descentralización, situación que no resulta ajena al sistema portuario, pueden citarse las de orden administrativo, tendentes a mejorar el funcionamiento del sistema burocrático del Estado, y, por otro lado, las de orden político, dado que supuestamente mejoran la participación ciudadana y refuerzan el control social en un espacio determinado.

${ }^{11}$ Desde la perspectiva económica, la concesión constituye un mecanismo institucional que actúa como barrera a la entrada a la actividad, establecida por el propio poder público. El uso de concesiones para sitios portuarios se fundamenta por la existencia de monopolios naturales. Las barreras a la entrada instituidas mediante concesiones limitan la competencia en el mercado, sea efectiva o potencial. La concesión implica la garantía de ciertos derechos o privilegios para el concesionario (por ejemplo la exclusividad en el manejo de una terminal), así como el conjunto de obligaciones que deben ser establecidas contractualmente. Las cláusulas contractuales toman la forma de normas regulatorias de ciertos aspectos desarrollados por la firma concesionaria (inversión, formas de uso, etc.). En consecuencia, la concesión no constituye necesariamente un sustituto de la regulación, sino que puede proporcionar la base legal para acciones regulatorias (Gorenstein, 2002: 28-29).

12 "Los puertos y terminales particulares que a la fecha de la promulgación de esta ley se encuentren en funcionamiento con autorización precaria otorgada por autoridad competente y conforme a las normas que regulan la materia, serán definitivamente habilitados por el poder Ejecutivo nacional, quien deberá comunicar esta decisión al
} 
Mediante el decreto 817/92 se instituyen las administraciones de los puertos de Rosario, Buenos Aires, Quequén, Bahía Blanca, Santa Fe y Ushuaia, como una forma de contribuir a la transferencia o privatización de los servicios portuarios y de las terminales ubicadas en cada uno de los puestos. También se instala la Subsecretaría de Puertos y Vías Navegables como autoridad portuaria nacional, y se disuelve la Administración General de Puertos (AGP) como el único organismo con facultades para administrar un puerto.

Las nuevas formas de administración y gestión asumen la figura jurídica de Consorcios de Gestión Portuaria. En esencia, esta reforma tiende a una creciente participación privada y a un predominio de los mecanismos de mercado en un espacio anteriormente considerado de dominio público. En este sentido, Fernando Romero Carranza (1993) señala que en la nueva legislación desaparece el término "servicio público", arraigado en la vieja concepción de la actividad portuaria, para concebirse como un servicio comercial. El término "público" se refiere al uso que puede darse a las instalaciones y no a la naturaleza del dominio de los servicios que ahí se prestan. En la ley se consagra otro principio fundamental, la libre competencia entre los puertos, en materia tanto de precios de los servicios como de la admisión de usuarios; se deja de lado el concepto de "tarifa" que le era propio al servicio público.

Desde el punto de vista organizativo, el cambio más importante es la conformación de entes y consorcios de gestión, cuyo fin es asegurar la participación de todos los sectores interesados en el quehacer portuario. ${ }^{13}$

Congreso Nacional dentro de los diez días hábiles contados a partir de la fecha de resolución" (Ley de Actividades Portuarias, art. 9). La ley consolida definitivamente el derecho y la libertad de los particulares para construir, operar y administrar puertos y prestar servicios portuarios, modificando sustancialmente el Código Civil y la situación preexistente de puertos solamente de dominio público nacional, y admite en forma expresa la categoría jurídica de los puertos nacionales, provinciales y municipales.

${ }^{13}$ La participación de todos los actores sociales que integran la comunidad portuaria está prevista en el decreto 769/93 que reglamenta la Ley Nacional de Actividades Portuarias núm. 24.093, donde se establece que las sociedades de derecho privado o entes públicos no estatales tienen a su cargo las siguientes responsabilidades: $a$ ) administrar, modernizar y explotar el puerto, lo que asegura la amplia participación y competencia del sector privado en la prestación de los servicios y evita prácticas desleales y monopólicas; $b$ ) garantizar la participación de todos los sectores públicos y privados involucrados en el quehacer portuario, y $c$ ) deben estar representados en los órganos de dirección de tal manera que se asegure su participación en la toma de decisiones. 
El Consorcio de Gestión del Puerto Quequén es dirigido y administrado por un directorio integrado por nueve miembros que duran tres años en sus funciones; pueden ser nuevamente designados sin límite de periodos, a la vez que pueden ser removidos antes del vencimiento de su cargo a pedido de las entidades que los propusieron (artículo $15^{\circ}$, capítulo VI, anexo II, Ley Provincial 11.414).

De acuerdo con la Ley Nacional de Actividades Portuarias núm. 24.093, el directorio del consorcio está conformado por el presidente -que es designado por el gobierno de la provincia de Buenos Aires-, un miembro que representa al municipio de $\mathrm{Ne}-$ cochea, cinco miembros que corresponden al sector privado ${ }^{14} \mathrm{y}$ dos miembros pertenecen a las asociaciones gremiales y sindicales que representan a los trabajadores.

Uno de los aspectos clave en la gestión del consorcio se refiere al proceso de toma de decisiones. En este sentido, la ley prevé que el directorio se reúna como mínimo cada 30 días; el quórum se constituye válidamente con la mitad más uno de sus miembros.

Las decisiones deben adoptarse por mayoría absoluta de los miembros presentes; en caso de empate, se computa doble el voto del presidente o de quien legalmente lo reemplace.

A partir de la sanción de la ley se garantiza, por medio de la figura de consorcio, la participación de actores clave en el proceso de decisión; sin embargo, por lo difuso de sus enunciados, por la pobreza de los acuerdos formulados y por la ausencia de un esquema regulatorio, ${ }^{15}$ se genera el ámbito propicio para acciones oportunistas por parte de algunos integrantes de la comunidad portuaria. Prueba de ello es la situación de conflicto, y aún no resuelta, por la falta de definición previa de las responsabili-

\footnotetext{
${ }^{14}$ Los cinco miembros del sector privado se distribuyen de la siguiente manera: un miembro por empresas concesionarias y permisionarias de las terminales; uno por las agencias marítimas; uno por las empresas prestadoras de los servicios de practicaje, amarre, estibaje y remolque; uno por las asociaciones que nuclean a los productores agropecuarios, y un miembro por los exportadores junto a la cámara industrial aceitera.

${ }^{15}$ La regulación constituye un conjunto de normas de carácter general y específico, y de acciones o procedimientos, emanados de estamentos políticos y de Estado que interfieren directa o indirectamente en las decisiones de oferta y demanda de los actores, lo que altera el libre juego de los mecanismos de mercado.

Los aspectos políticos de la regulación se relacionan esencialmente con la discusión de los objetivos que deben guiar las acciones de intermediación en actividades y mercados, que terminan plasmándose en principios y disposiciones regulatorias. Por su dimensión legal se vincula con la constitución de marcos institucionales y el establecimiento de disposiciones generales y específicas para el funcionamiento de las actividades, así como con la definición de procedimientos administrativos de control y fiscalización (Gorenstein, 2002: 28-29).
} 
dades de las partes, especialmente frente al pago del canon ${ }^{16}$ por parte de los actuales operadores del puerto, ya que el único instrumento de acuerdo y regulación surge del pliego de licitación, donde por razones, voluntarias o no, no fue especificado si debía pagarse a la provincia o al consorcio. Mientras tanto, el monto permanece en caución hasta que la justicia determine su destino. Esto posterga el proceso de modernización e inversión en el puerto y mantiene latente una fuente de conflicto.

\subsection{El sector privado en la nueva organización portuaria}

Entre los integrantes del Consorcio de Gestión pertenecientes al sector privado se encuentran las principales empresas exportadoras de granos, aceites y subproductos de la industria aceitera, así como las agencias marítimas. Estas últimas son las empresas que brindan servicios a los buques y a los exportadores, y su principal función es coordinar los servicios de los prácticos y lanchas de remolque para la entrada y salida de los buques al puerto.

Entre las primeras se distingue la empresa transnacional Cargill, que emplazó su planta de transformación de aceites de girasol a principios de los años ochenta, al igual que lo hizo en el puerto de San Martín, en la ribera del río Paraná. En 1992, esta empresa exportaba 17\% del volumen que pasaba por Quequén, y actualmente alcanza $20 \%$ del total exportado y $24 \%$ de las importaciones de fertilizantes que ingresan a este puerto. Le siguen en importancia: Nidera, con $16 \%$ de las exportaciones; la ACA, con una participación de 10\%, y Necochea/Quequén, con 6\% de las exportaciones totales del puerto.

Actualmente, los principales exportadores en orden de importancia son: Cargill (20\%), Toepfer y Tradigrain (15\%), ACA (11\%), Dreyfus y Omsha (10\%), y Nidera (8\%); en tanto las firmas importadoras, principalmente de fertilizantes, son: Agroservicios Pampeanos (15\%), Profertil (10\%) e Hydro (7\%).

Si se compara el número de empresas exportadoras que operaban en Quequén antes del proceso de privatización, y las que operan en el año 2001, se comprueba que a principios de los noventa, cuatro empresas (Cargill, Nidera, ACA y Necochea/Quequén) concentraban alrededor de $50 \%$ de las exportaciones, mientras que en el año 2001, seis empresas captan 80\% (Cargill, Teopfer, Tradigrain, Dreyfus, Omhsa y Nidera); la mitad de este

${ }^{16}$ Pago fijo por el aprovechamiento de una concesión pública. 
porcentaje corresponde a las firmas de origen extranjero. De acuerdo con el índice de Bain, ${ }^{17}$ que calcula el grado de concentración en función del número y distribución por tamaño de las firmas, se comprueba que en 10 años se ha pasado de un grado de concentración moderadamente bajo, donde cuatro empresas controlaban alrededor de 50\% de las exportaciones a un grado de concentración alto.

Este proceso es congruente con el grado de concentración y transnacionalización operado en la economía argentina durante los noventa, y le otorga a estas firmas un fuerte poder de negociación en la correlación de fuerzas dentro del consorcio.

En la operatoria portuaria de Quequén surge una clara preeminencia de las grandes firmas comercializadoras de commodities en el ámbito internacional sobre las firmas de capital nacional. Sin embargo, cabe destacar la estrategia desarrollada por ACA, que, al igual que Cargill, supo anticiparse durante la etapa preprivatizadora (periodo comprendido entre 1980-1991) con inversiones tendentes a asegurarse un emplazamiento estratégico en las principales zonas de embarque, a fin de captar los aumentos de producción asociados al proceso de agriculturización. En el mismo sentido, durante esa etapa las industrias aceiteras de exportación Cargill y Omsha (Oleaginosa Moreno) emplazaron sus industrias sobre este puerto para aprovechar un abastecimiento cercano y agregar valor a los productos. En cambio, durante la etapa de privatización estas dos empresas privilegian la localización de sus plantas de transformación sobre el puerto de Bahía Blanca.

Las inversiones realizadas por ACA en la terminal portuaria le permitieron captar durante el año 2001, en promedio, 55\% de los embarques, mientras que Terminal Quequén ejerce 17\%; el $28 \%$ restante corresponde a la terminal de fertilizantes y a las cargas que se efectúan por embarque directo. ${ }^{18}$

\footnotetext{
${ }^{17} \mathrm{El}$ índice de Bain relaciona los volúmenes manejados por las cuatro y ocho empresas más grandes con lo operado por la totalidad de las firmas. El resultado se compara con los valores asignados a cinco categorías establecidas: $a$ ) grado de concentración muy alto: las tres o cuatro empresas controlan una porción muy alta del producto; $b$ ) grado de concentración alto: las ocho empresas de mayor tamaño controlan de 85 a 90\%, y las cuatro empresas más grandes, de 65 a $70 \% ; c$ ) grado de concentración moderadamente alto: las ocho empresas más grandes controlan entre 70 y $85 \%$ de las operaciones, y las cuatro de mayor tamaño, entre 50 y $65 \%$; $d$ ) grado de concentración moderadamente bajo: las ocho empresas de mayor tamaño controlan entre 45 y $70 \%$, y las cuatro más grandes, entre 35 y $50 \%$, y e) grado de concentración bajo: menos de 35\% es controlado por las cuatro empresas más grandes, y menos de $45 \%$ por las primeras ocho empresa; en general existe un grupo numeroso de pequeñas empresas.

${ }^{18}$ Muelle por donde puede embarcar cualquier terminal.
} 
Otro agente de importancia dentro de la comunidad portuaria son las agencias marítimas. En este puerto operan siete agencias, las principales son Pleamar, Brisamar y Serviport, que en conjunto captan 75\% de los embarques; disponen también de la información justo a tiempo de los buques que van a ingresar al puerto y de los sitios que se encuentran disponibles. Esta información les otorga un mayor poder de negociación frente a los exportadores, pues además tienen integrados todos los servicios y a la vez son despachantes de aduana.

\section{Articulación público/privada en la organización del puerto Quequén}

La comunidad portuaria es, en la práctica, la alianza de todos los principales grupos de la zona portuaria, en la que defienden sus intereses y promueven y coordinan sus actividades (Gorenstein, 2002: 35). A partir del análisis de la evolución en la conformación y funcionamiento del Consorcio de Gestión del Puerto Quequén, se profundiza en la comprensión de esta experiencia de organización desde la perspectiva sociológica de Bourdieu (1999). Para ello, como se mencionó anteriormente, se utilizan las nociones de campo (la comunidad portuaria como tal) y de capital, que en este caso está representado por el capital sociopolítico y el económico, los que en conjunto conforman el capital global de la organización.

En la corta trayectoria de la organización, la estructura de gobernación del puerto se ha complejizado, y al mismo tiempo se asiste a un incremento del capital global como resultado de la incorporación de nuevos actores en el proceso de toma de decisiones y en la experiencia y aprendizaje que ha significado la gestión público/privada.

El capital global de la organización ha crecido en términos del capital económico con la participación de un mayor número de empresas exportadoras e importadoras, que han aumentado su escala de operaciones (volumen de cargas y monto de facturación) y también han crecido en capital sociopolítico mediante aspectos no tangibles como el aprendizaje logrado en 10 años de elaboración y ejecución de propuestas, y la toma de decisiones en un ámbito compartido y en ciertas oportunidades la resolución de conflictos. 
A lo largo de este periodo es posible distinguir dos etapas diferenciadas en función de la primacía de algún capital o recurso específico que ejercen algunos de los agentes participantes.

Para el análisis de cada etapa se recurre a un diagrama (véase diagrama I) que representa el capital global de la organización, donde la relación entre el capital económico y el capital sociopolítico define cuatro cuadrantes. Así, en el cuadrante i se refleja el dominio del capital económico sobre el capital sociopolítico; por el contrario, en el cuadrante IV se muestra que el capital sociopolítico se impone sobre el económico, mientras en los cuadrantes II y III ni el capital económico ni el capital sociopolítico logran supremacía uno sobre otro.

\section{Diagrama I \\ Conformación del campo portuario (periodo 1994-1997) Capital global}

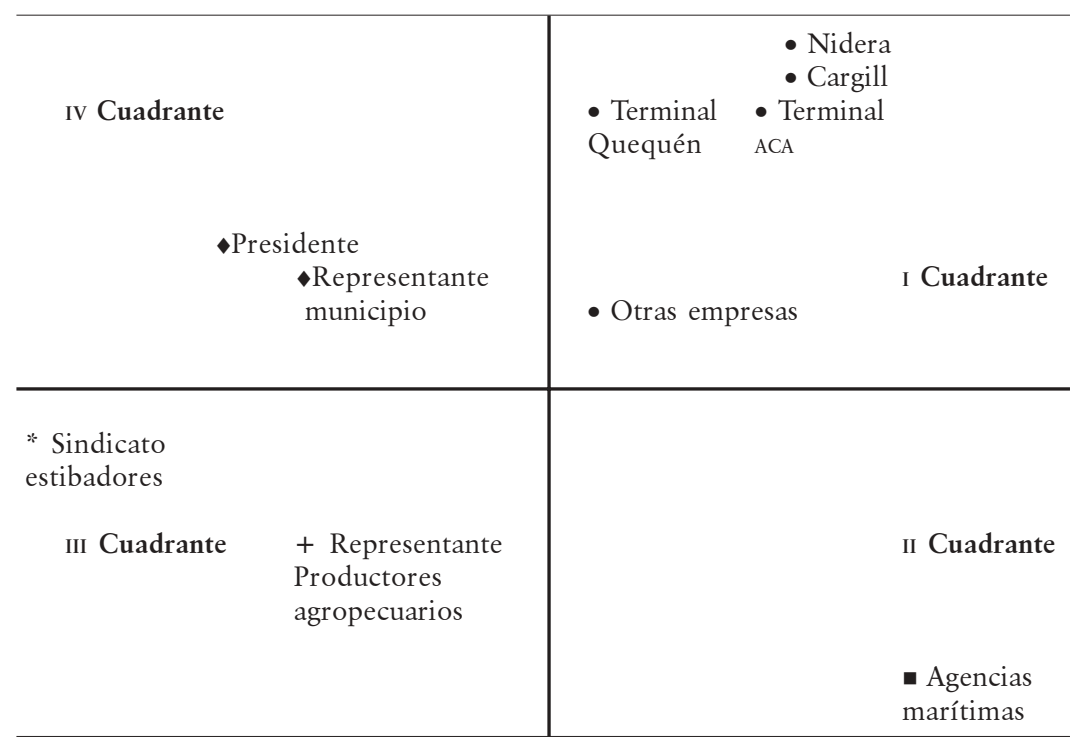

Referencias:

Capital sociopolítico: - Agentes sector público; + Representantes productores;

* Sindicatos.

Capital económico: $\Delta$ Terminales elevadores de granos; • Exportadores; - Agencias marítimas.

Cuadrante I: + Capital económico - Capital sociopolítico.

Cuadrante II: - Capital económico - Capital sociopolítico.

Cuadrantes III: - Capital sociopolítico - Capital económico.

Cuadrante Iv: + Capital sociopolítico - Capital económico.

Fuente: Elaboración propia con base en entrevistas y revisión de periódicos locales, regionales y nacionales. 
La ubicación de los distintos actores dentro del campo de la organización se realiza en forma subjetiva según la información que surge de las entrevistas y el seguimiento en periódicos tanto nacionales como locales.

En un primer momento, relacionado con el inicio de la primera gestión del consorcio, que abarca desde 1994 hasta 1997, se destaca la importancia que adquiere el capital económico sobre el sociopolítico, en concordancia con el discurso privatizador que enfatiza la supuesta eficacia de los propios actores y la escasa capacidad asignada al sector público como administrador.

\section{Diagrama II \\ Conformación del campo portuario (periodo 1997-2003) Capital global}

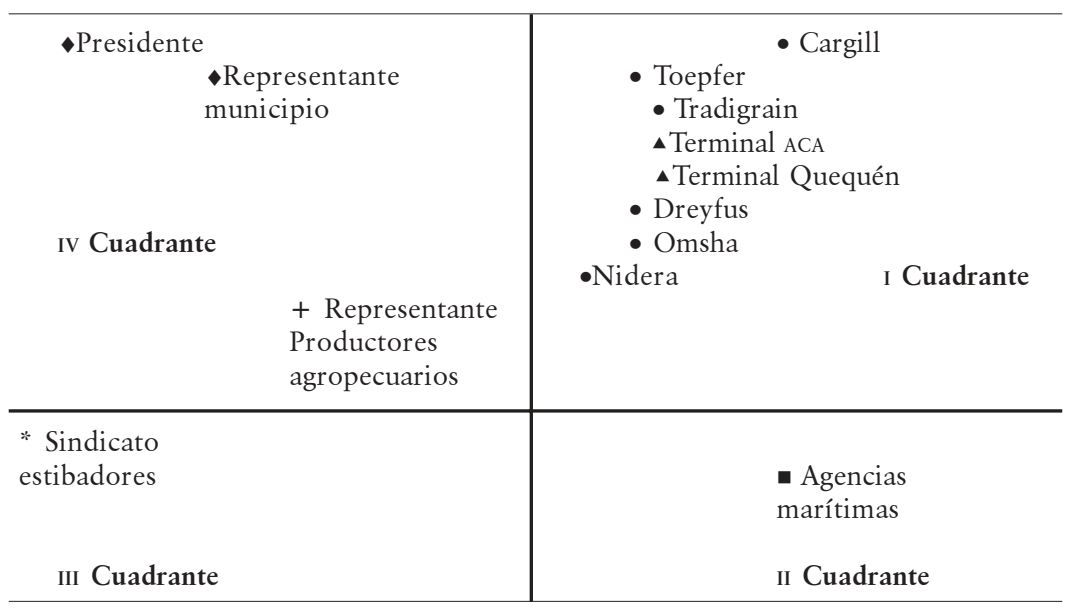

Referencias:

Capital sociopolítico: - Agentes sector público; + Representantes productores;

* Sindicatos.

Capital económico: \Terminales elevadores de granos; • Exportadores; - Agencias marítimas.

Cuadrante I: + Capital económico - Capital sociopolítico.

Cuadrante II: - Capital económico - Capital sociopolítico.

Cuadrantes III: - Capital sociopolítico - Capital económico.

Cuadrante Iv: + Capital sociopolítico - Capital económico.

Fuente: Elaboración propia con base en entrevistas y revisión de periódicos locales, regionales y nacionales.

En esta etapa, el crecimiento del capital global depende en gran medida de la presencia de capital económico, representado en este caso por las dos filiales de empresas transnacionales (Cargill y 
Nidera) y los capitales nacionales de ACA y de las firmas exportadoras que componen el capital accionario de Terminal Quequén.

Durante esta etapa, el presidente, el gerente y los representantes de los trabajadores tienen una postura relativamente pasiva frente a las decisiones de reconstrucción e inversión en nuevas instalaciones para volver competitivo al puerto.

En este periodo, el capital sociopolítico cobra relevancia en manos del sindicato de estibadores, que a pesar de la política de transferencia de personal y del programa de retiro voluntario puesto en práctica en el país, logran, por el grado de organización y sindicalización, conservar la misma estructura de personal del periodo estatizador, hecho que diferencia al sindicato de este puerto de otros del país.

En cuanto a los representantes de los productores agrícolas, en esta etapa poseen una participación formal y bastante pasiva en relación con el capital sociopolítico que poseen, situación que se revierte especialmente para los representantes de las entidades agrarias en la medida que comienzan a percibir al puerto como un espacio estratégico para defender y mantener la eficiencia lograda en la producción agrícola.

En la siguiente etapa, que comprende de 1997 a la fecha, existe un cambio en las relaciones de poder dado el papel protagónico que asumen los representantes políticos (el presidente y el delegado del municipio), con base en el capital sociopolítico que cada uno de ellos asume (véase el diagrama II).

En este periodo, el funcionario a cargo de la presidencia-que siempre se asigna a una figura local- acrecienta el capital sociopolítico, por el apoyo y decisión del poder político provincial. Una lógica similar se observa con el representante del municipio de Necochea, quien es elegido por el presidente del consorcio y también es un político de raigambre local. En este marco, aumenta el recurso sociopolítico local en detrimento del poder económico global.

Una explicación a este cambio puede asociarse con dos causas, que aunque de distinta índole pueden afectar simultáneamente las condiciones de estructura del campo de la organización. Por un lado, frente a los resultados de las privatizaciones de los servicios públicos, la sociedad argentina percibe un agotamiento de las bondades del discurso privatizador. Por otro, los partícipes del gerenciamiento del consorcio comienzan a sentir estos efectos y a desgastarse cuando se ahondan en el seno de la organización los conflictos de interés entre los participantes, es- 
pecialmente de aquellos que no están dispuestos a resignar sus utilidades en la inversión de infraestructura básica que le correspondía al Estado nacional.

Por otra parte, a lo largo de la experiencia, los privados toman conciencia de la magnitud de una administración de esta naturaleza, que en un principio subestimaron porque confiaban en que los mecanismos del libre mercado asignarían correctamente los recursos. El paso del tiempo pone de manifiesto la incapacidad del mercado para dirimir los conflictos en un sistema donde las decisiones deben ser compartidas con otros grupos de interés con distinto poder de negociación.

El relativo repliegue del capital económico también se relaciona con la lógica de inversión de las filiales de las empresas transnacionales participantes del consorcio, que con una perspectiva global y desterritorializada empiezan durante esta etapa a dar prioridad, como estrategia de reinversión de las utilidades, a otros puertos del país que les ofrecen mayor rentabilidad. Así, a Quequén le corresponde un lugar secundario en el proceso de localización de las nuevas inversiones. A este proceso se suma el hecho de que las firmas líderes comienzan a tener mayor competencia por parte de otras empresas exportadoras e importadoras que operan en este puerto, lo que en cierta medida debilita el poder más concentrado de la primera etapa. Prueba de ello es la orientación de las inversiones de Cargill en el puerto de Bahía Blanca y la reconversión de empresa exportadora a importadora de insumos agropecuarios de Nidera en Argentina. También en esta etapa, las agencias marítimas contribuyen al capital económico, ya que asumen un mayor número de funciones en el proceso de comercio exterior (despachantes de aduana y contratación de los servicios de practicaje y pilotaje, entre otras), y juegan un rol más estratégico al concentrar más poder económico y de negociación frente a los exportadores.

Otro elemento distintivo de esta etapa es la necesidad del Estado provincial de insertarse más activamente en el espacio de decisión que ofrece el consorcio y de la participación en la distribución de los beneficios que genera. Mediante la transferencia de la nación a la provincia, y de ésta al consorcio, se delegan deliberadamente las funciones de inversión y acumulación hacia el sector privado, situación que más tarde se revierte en poder político por la habilidad que éste posee en la mediación de los conflictos a cambio de la participación en la captación de beneficios. Este cambio se percibe más como una estrategia deliberada 
del poder político para acrecentar su capital sociopolítico y también económico, más que como una postura que tienda a mantener y garantizar las funciones indelegables del Estado. Al respecto cabe recordar que el campo no es una estructura autónoma, sino que existe cierta sobredeterminación del contexto sociopolítico general, o mejor dicho, las relaciones de fuerzas pueden estar influidas por las condiciones macroeconómicas y sociopolíticas imperantes.

Otros actores que también adquieren relevancia en esta segunda etapa son los representantes de los productores agropecuarios, que asumen un papel más activo en el proceso de toma de decisiones. Este hecho puede explicarse según la entidad y su grado de representatividad durante su participación en la mesa de negociación del consorcio.

Durante la primera etapa, el representante de este sector es un miembro de la Confederación Intercooperativa Agropecuaria (Coninagro), que por ser una entidad de tercer grado, es decir, una confederación de federaciones, no sufre durante su gestión las presiones directas de los asociados, y además su participación está fuertemente eclipsada por las decisiones de la terminal ACA, que es miembro de esta confederación.

En cambio, en un segundo momento, quien representa a los productores es un miembro de Confederaciones Rurales Argentinas (CRA), que normalmente tiene una postura más combativa por el capital sociopolítico, proveniente de la estrecha relación con sus asociados que pertenecen a las sociedades rurales locales, la cual les confiere cierto status social en esta comunidad.

En cuanto al rol de los sindicatos en la última etapa, se verifica que éstos pierden protagonismo en términos de los reclamos, dado que no ven amenazada su fuente de trabajo, aunque mantienen su capital gracias al respaldo que reciben del presidente del consorcio a cambio de su legitimidad política.

\section{Consideraciones finales}

Como conclusión, a continuación de presenta un conjunto de reflexiones respecto a la especialización y eficiencia económica alcanzada por el puerto Quequén, la participación de los actores y la existencia de lógicas diferentes derivadas de intereses contrapuestos, así como las potencialidades, límites y gobernabilidad del sistema portuario. 
En primer lugar, a partir de la acción público/privada en el puerto de Quequén, se verifican signos positivos en los indicadores de eficiencia económica que otorgan mayor competitividad a este puerto.

En este sentido, a la reducción de los días de espera -que pasan de ocho días en la década de los ochenta a dos de los noventa- se suma la reducción de los costos por el uso del muelle y la operación de buques de mayor escala por las obras de dragado. No obstante, la especialización productiva del puerto asociada a la producción primaria de la zona, junto al desmantelamiento de la red ferroviaria que converge en el puerto, marcan un límite a la expansión del hinterland.

De la información de campo recogida se desprende que no existían en el seno del consorcio acciones tendentes a realizar las inversiones y promover políticas de infraestructura para mejorar la posición de este puerto frente a otros puertos competidores.

En segundo lugar, la descentralización promueve una nueva forma organizativa por medio de entes que tienden a asegurar la participación de todos los sectores interesados en el quehacer portuario, tales como operadores, prestadores de servicios, productores, usuarios y trabajadores vinculados a la actividad, además de los miembros del sector público que representan a la provincia y al municipio donde se encuentra emplazado el puerto. Esto implica un cambio en las reglas del juego y en la toma de decisiones entre todos los agentes involucrados.

En relación con este último punto, durante los primeros años dentro del Consorcio de Gestión existe una mayor cohesión en las decisiones y acciones llevadas a cabo. Es posible que esta coherencia se deba en gran parte a la fuerza que a principios de los noventa tiene el discurso privatizador y al entusiasmo inicial del sector privado basado en la supuesta eficiencia mayor y capacidad de este sector para realizar cambios estructurales. Esta lógica de mercado va más allá del Estado-nación, y demuestra que la competencia comienza a involucrar los contextos institucionales.

Un tema pendiente de resolución tiene que ver con el pago del canon por parte de la Terminal Quequén, dado que no existe acuerdo entre el consorcio y la provincia respecto a quién le corresponde el cobro. Como resultado, el monto se encuentra en caución en la justicia.

Más tarde, frente a los primeros signos de la crisis económica, surgen las primeras divergencias entre el sector público y el sector privado en cuanto a las inversiones por realizar y a la distribución 
y aplicación de los excedentes generados. Esta divergencia entre una lógica de mercado y una lógica política está ligada a las prioridades que cada sector asigna y tiene sobre las utilidades generadas. Mientras los empresarios no están dispuestos a continuar resignando utilidades y a enfrentar las nuevas inversiones, los funcionarios parecen más preocupados por mantener y ejercer el poder, con la búsqueda de reconocimiento de la comunidad y, en algunos casos, mediante el clientelismo político.

Por otra parte, en la trayectoria de la organización del puerto Quequén es posible afirmar que impera una lógica local/territorializada sobre la global en la toma de decisiones, dada la búsqueda de legitimidad en la comunidad en la elección y conformación del Consorcio de Gestión, que siempre da prioridad a miembros de raigambre local en su presidencia.

Esta lógica se contrapone con la estrategia de inversión y localización desplegada por las empresas transnacionales, que al participar en distintos puertos del país y del mundo, cuentan con mayor información que les permite garantizar mayores retornos a la inversión y que, en última instancia, pueden decidir quién gana y quién pierde en la competencia interportuaria. Hasta ahora, este puerto no parece ocupar un lugar destacado en las decisiones de esas firmas, aunque éstas mantienen su presencia en él.

La tensión entre el capital sociopolítico y el económico hace prever una agudización de los conflictos en el seno del consorcio atribuible a problemas de información e incentivos derivados de la articulación y diseño regulatorio, donde no se consideran la existencia de asimetrías informativas, acción de grupos de interés, atenciones políticas, debilidades institucionales y cierto grado de discrecionalidad que subsiste en la interpretación de los contratos y marco regulatorio. Esta tensión atenta contra la gobernabilidad del sistema de cooperación conjunta entre la actividad privada y la pública.

Para finalizar, la existencia de reglas claras en la negociación dentro de la organización permitirá afianzar el dinamismo alcanzado en el corto tiempo transcurrido desde la conformación del Consorcio de Gestión en 1994; además, se considera que aún existen potencialidades y es necesario encarar acciones más proactivas por parte de esta organización que otorguen mayor competitividad al puerto y que profundicen la experiencia de gestión conjunta. 


\section{Bibliografía}

Bourdieu, Pierre (1999), Intelectuales, politica y poder, EUDEBA, Buenos Aires.

Cepal (Comisión Económica para América Latina y el Caribe) (1992), La reestructuración de empresas públicas: el caso de los puertos de América Latina y el Caribe, Cuadernos de la Cepal 68, Publicación de Naciones Unidas, Chile.

Costa, Ana María (2003), Nuevas formas de organización y gestión del sistema portuario argentino en la década del 90: competitividad y eficiencia del Puerto Quequén, tesis de maestría, Facultad de Ciencias Agrarias, Universidad Nacional de Mar del Plata.

FIEL (Fundación de Investigaciones Económicas Latinoamericanas) (1999), La regulación de la competencia y de los servicios públicos. Teoría y experiencia Argentina reciente. FIEL, Buenos Aires.

Gardel, Cristian (1999), Puertos graneleros en la Argentina, algunos indicadores de performance portuaria, Bolsa de Comercio de Rosario, Serie de Lecturas 3, Rosario, Argentina.

Gorenstein, Silvia (2002), Tres estudios sobre la perspectiva institucional en el sector portuario. Análisis referencial para el puerto de Buenos Aires, Programa de Desarrollo Económico Territorial (Prodet)-Secretaría de Desarrollo Económico del Gobierno de la Ciudad de Buenos Aires-Programa de Naciones Unidas para el Desarrollo (PNUD), Buenos Aires.

Hoffmann, Jan (1999), Las privatizaciones portuarias en América Latina en los 90: determinantes y resultados, documento de trabajo, Tercer Programa Internacional, Privatización y Regulación de Servicios de Transporte del Banco Mundial, Las Palmas, Gran Canarias, España.

Romero Carranza, Fernando (1993), "Los puertos privados particulares en la nueva legislación portuaria”, Bolsa de Comercio de Rosario, diciembre, año XL (1461): 12-20. 
Sagpya (Secretaría de Agricultura, Ganadería, Pesca y Alimentación) (2002), Principales puertos cerealeros. Evolución operativa, 1990-2000, Dirección de Mercados Agroalimentarios, Buenos Aires.

Thomson, Ian (1998), "La evolución del papel del Estado en la regulación del transporte terrestre", Revista de la Cepal, abril, 64: 151-163.

Trujillo Lourdes y Gustavo Nombela (2000), Multiservice Infrastructure Privatizing Port Service, The World Bank Group, Private Sector and Infrastructure Network, note number 222, octubre.

Recibido: 20 de junio de 2005. Reenviado: 9 de septiembre de 2005. Aceptado: 10 de septiembre de 2005.

Ana María Costa es magister scientiae en agroeconomía, con orientación en comercialización y marketing agroalimentario por el Programa de Posgrado en Agroeconomía, Facultad de Ciencias Agrarias de la Universidad Nacional de Mar del Plata. Sus líneas actuales de investigación se dirigen a la comercialización y las políticas agrícolas, transporte y logística agroalimentaria. Entre sus publicaciones recientes se cuentan: con S. Brieva y L. Iriarte (2003), "Gestión y regulación de los servicios e infraestructura portuaria en el desarrollo económico argentino", Problemas del Desarrollo, revista latinoamericana de economía, Instituto de Investigaciones Económicas, Universidad Nacional Autónoma de México, 34 (135): 29-47; y con las mismas coautoras (2001), "Intercambio comercial agroalimentario argentino", Políticas Agrícolas, núm. 11, revista de la Red de Instituciones Vinculadas a la Capacitación en Economía y Políticas Agrícolas en América Latina y el Caribe (Redcapa), Bogotá, Colombia, pp. 85-118.

Susana Silvia Brieva tiene la maestría en ciencias sociales por la Facultad Latinoamericana de Ciencias Sociales (Flacso) Costa Rica, y es candidata a doctora en ciencias sociales en Flacso Buenos Aires. Son sus líneas de investigación: comercialización y políticas agrícolas, transporte y logística agroalimentaria. Publicaciones recientes: "Relaciones contractuales y eficiencia en la 
comercialización de trigos de calidad panadera", Investigaciones, revista de la Facultad de Ciencias Agrarias de Rosario, año 4, núm. VI, diciembre, pp. 15-25, con J. Llorens, L. Iriarte y J. Fangio (2004); "Gestión y regulación de los servicios e infraestructura portuaria en el desarrollo económico argentino", Problemas del Desarrollo, revista latinoamericana de economía, Instituto de Investigaciones Económicas, Universidad Nacional Autónoma de México, 34 (135): 29-47, con A. Costa y L. Iriarte (2003); y con estas últimas (2001), "Intercambio comercial agroalimentario argentino" Políticas Agrícolas, núm. 11, revista de la Red de Instituciones Vinculadas a la Capacitación en Economía y Políticas Agrícolas en América Latina y el Caribe (Redcapa), Bogotá, Colombia, pp. 85-118.

Liliana Iriarte estudió la maestría en ciencias sociales en la Facultad Latinoamericana de Ciencias Sociales (Flacso) Costa Rica. Como líneas de investigación tiene la comercialización y las políticas agrícolas, el transporte y la logística agroalimentaria. Se cuentan entre sus pulicaciones: con J. Llorens, S. Brieva y J. Fangio (2004), "Relaciones contractuales y eficiencia en la comercialización de trigos de calidad panadera", Investigaciones, revista de la Facultad de Ciencias Agrarias de Rosario, año 4, núm. vI, diciembre, pp. 15-25; con A. Costa y S. Brieva (2003), "Gestión y regulación de los servicios e infraestructura portuaria en el desarrollo económico argentino", Problemas del Desarrollo, revista latinoamericana de economía, Instituto de Investigaciones Económicas, Universidad Nacional Autónoma de México, 34 (135): 29-47; y también con A. Costa y S. Brieva (2001), "Intercambio comercial agroalimentario argentino", Políticas Agrícolas, núm. 11, revista de la Red de Instituciones Vinculadas a la Capacitación en Economía y Políticas Agrícolas en América Latina y el Caribe (Redcapa), Bogotá, Colombia, pp. 85-118. 